\title{
O PLANO DIRETOR DE ILHA SOLTEIRA - SP COMO NORTEADOR DO DESENVOLVIMENTO DO TURISMO
}

\author{
Renata Maria Ribeiro ${ }^{1}$
}

\author{
Pedro Henrique Botelho de Souza ${ }^{2}$
}

Fábio Luciano Violin ${ }^{3}$

\begin{abstract}
RESUMO
O turismo é foco de estudo de ciências consolidadas que atualmente dão suporte à pesquisa aplicada dos elementos que influenciam o desenvolvimento e interferem no modo de vida populações tanto de modo positivo, quanto negativo, se, não planejado. No Brasil, a organização das cidades podem ser iniciadas por políticas de desenvolvimento a exemplo do Plano Diretor, que traça as diretrizes nas diversas esferas da ordem pública. O Plano é considerado um instrumento político de desenvolvimento e expansão urbana. O presente trabalho objetivou estudar o Plano Diretor da Estância Turística de llha Solteira - SP, observando as diretrizes para o desenvolvimento do turismo. Dentre as atividades previstas para atingir os resultados, fez-se necessário buscar conteúdos com intuito de aprimorar o conhecimento sobre temas como planejamento, Plano Diretor e Turismo; e aplicar a metodologia SWOT para projetar um cenário com respostas norteadoras ao aperfeiçoamento das políticas públicas para o desenvolvimento do turismo no município. As informações verificadas sobre llha Solteira, nos meios eletrônicos, inventário turístico e na visita ao município, permitiu entender um pouco da sua realidade, dos atrativos, monumentos, eventos, espaços públicos em que há movimentação de visitantes, bem como algumas ações da gestão municipal para fomento do turismo. Observou-se então após análise que as diretrizes do Plano Diretor aliadas às ferramentas do planejamento do turismo, são imprescindíveis a uma forma de gestão contínua, norteadora e fortalecedora da atividade em Ilha Solteira - SP.
\end{abstract}

PALAVRAS-CHAVE: Plano Diretor, Turismo, Planejamento.

\section{THE MASTER PLAN OF ILHA SOLTEIRA -SP AS A GUIDE TO TOURISM DEVELOPMENT}

\footnotetext{
${ }^{1}$ Doutora em Geografia,UNESP, Câmpus Rosana/Professora. renata@rosana.unesp.br

${ }^{2}$ Graduando em Turismo, UNESP, Câmpus Rosana/Discente. pedro.tur10.unesp@hotmail.com

${ }^{3}$ Mestre em Administração,UNESP Câmpus Rosana/Professor. violin@rosana.unesp.br
} 


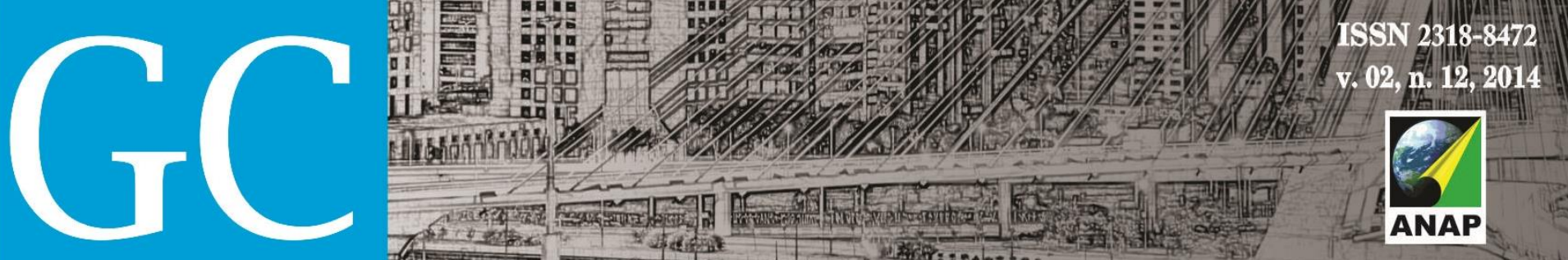

Revista Nacional de

Gerenciamento de Cidades

\begin{abstract}
Tourism is focus of study consolidated sciences that currently support the applied elements that influence the development research and interfere with the way of life of populations both positive, and negative, if not planned. In Brazil, the organization of cities can be initiated by development policies such as the Master Plan, which outlines the guidelines in many spheres of public order. The Plan is considered a political tool of development and urban sprawl. The present study investigated the Master Plan the tourist city of llha Solteira - SP, within the guidelines for the development of tourism. Among the activities planned to achieve the results, it was necessary to seek content with the aim of improving the knowledge on topics such as planning, Master Plan and Tourism; and apply the SWOT methodology to design a scenario with guiding the improvement of public policies for the development of tourism in the municipality answers. The verified information about Single Island, in electronic media, tourism inventory and visit the municipality allowed to understand a little of its reality, the attractions, monuments, events, public where there is movement of visitors spaces, as well as some actions of municipal management for promoting tourism. They established after analyzing the Director Plan allied to tourism planning tools are essential to a form of continuous management, guiding and empowering activity in llha Solteira - SP.
\end{abstract}

KEY-WORDS: Master Plan, Tourism, Planning.

\title{
EI PLAN MAESTRO DE ILHA SOLTEIRA-SP COMO UNA GUÍA PARA DESARROLLO TURÍSTICO
}

\section{RESUMEN}

El turismo es objeto de estudio de ciencias consolidadas y en la actualidad dan soporte a la investigación aplicada de los elementos que influyen en el desarrollo e interfieren en el modo de vida de las poblaciones tanto de manera positiva como negativa, si no planificado. En Brasil la organización de las ciudades pueden ser iniciadas por las políticas de desarrollo, tales como el Plan Maestro, que esboza las directrices en los distintos ámbitos de orden público. El Plan es considerado un instrumento político de desarrollo y expansión urbana. El presente trabajo tuvo como objetivo estudiar el Plan Maestro de la Estância Turística de Ilha Solteira - SP, observando las directrices para el desarrollo del turismo. Entre las actividades previstas para lograr los resultados, fue necesario obtener el contenido con el fin de mejorar el conocimiento sobre temas tales como planificación, Plan Maestro y Turismo y aplicar la metodología DAFO para diseñar un escenario con respuestas orientadoras al mejoramiento de las políticas públicas para el desarrollo del turismo en el municipio. Las informaciones en los medios electrónicos, inventario turístico y en la visita al municipio ha permitido comprender un poco de su realidad, de sus atractivos, monumentos, eventos, espacios públicos donde hay movimiento de visitantes, además de algunas acciones de la gestión municipal para el fomento del turismo. Se observó, a continuación, después del análisis de las directrices que el Plan Maestro aliado de los instrumentos de planificación del turismo son indispensables para una forma de gestión continua para guiar y que fortalecer la actividad en Ilha Solteira -SP.

PALABRAS-CLAVE: Plan Maestro, Turismo, Planificación. 
Revista Nacional de

Gerenciamento de Cidades

\section{INTRODUÇÂO}

O planejamento territorial das cidades determina ações a serem executadas às prerrogativas legais que devem ser consideradas ao estabelecimento de normas a serem seguidas para a condução ordenada das cidades.

No Brasil, a organização das cidades podem ser iniciadas por políticas de desenvolvimento a exemplo do Plano Diretor, que traça as diretrizes nas diversas esferas da ordem pública.

O Plano Diretor é considerado um instrumento político de desenvolvimento e expansão urbana. No Estatuto da Cidade é considerado como integrante do próprio planejamento municipal. A partir dele ficam estabelecidas as condições de ordenamento do território. No Capítulo III Art. 41 do Estatuto da Cidade (2004), aponta os fatores que determinam a elaboração de um Plano Diretor, tornando-o, então, obrigatório em cidades

\footnotetext{
I - com mais de vinte mil habitantes;

II - integrantes de regiões metropolitanas e aglomerações urbanas;

III - onde o Poder Público municipal pretenda utilizar os instrumentos previstos no $4^{\circ}$ do art. 182 da Constituição Federal;

IV - integrantes de áreas de especial interesse turístico;

$\mathrm{V}$ - inseridas na área de influência de empreendimentos ou atividades com significativo impacto ambiental de âmbito regional ou nacional.
}

Observe-se que a Lei institui a necessidade da elaboração desse documento em áreas em que há interesse turístico; partindo deste pressuposto, a atividade turística numa determinada localidade não deve desenvolver de modo desconexo deste instrumento.

Entende-se que é pertinente aliar o planejamento territorial ao desenvolvimento políticas públicas municipais a partir dos planos diretores se faz necessário, uma vez que podem servir de suporte legal à execução de planos de desenvolvimento para a população e turistas. 

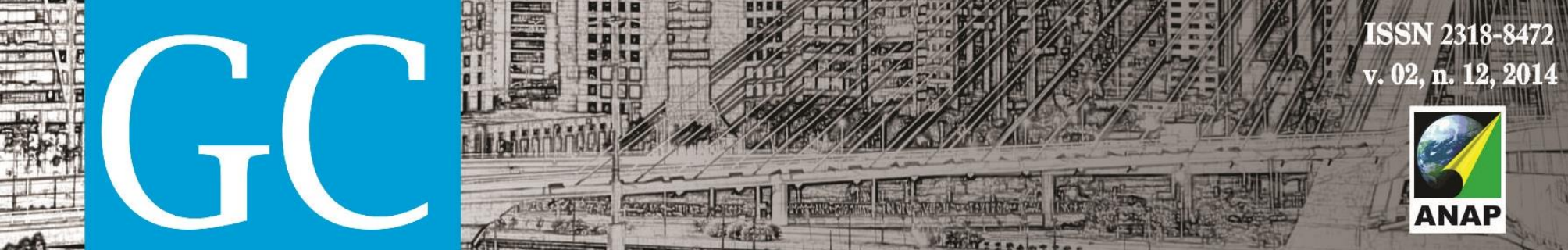

Revista Nacional de

Gerenciamento de Cidades

principais atrativos, as praias artificiais e o rio; consequentemente esse tipo possui de turismo possui alta e baixa temporada diante das estações do ano com a redução de movimento de visitantes. Certamente, novas possibilidades de investimento e planejamento de eventos poderiam ser estudados com o intuito de compensar os impactos da sazonalidade, ampliando o calendário oficial dos mesmos.

Percebe-se também, o envolvimento de outros departamentos, além do turismo, que contribuem direta e indiretamente ao desenvolvimento da atividade no município; cabe citar, o departamento de Esportes e o Departamento de Cultura, que realizam atividades que provocam a chegada e movimentação de visitantes ao município.

No entanto, ainda, não se pode afirmar que há uma articulação planejada entre as respectivas secretarias.

Os recursos naturais e culturais podem se transformarem em atrativos, e constituírem parte do patrimônio turístico, que são "elementos passíveis de provocar deslocamentos de pessoas, e que integram o marco geográfico-ecológico-cultural de um lugar, podendo, por sua origem, ser subdivididos em naturais e culturais."(BENI, 2007, p. 59).

No município de llha Solteira existem os atrativos artificiais, que correspondem às praias Marina e Catarina, que embora artificiais, utilizam-se dos recursos naturais, ou seja, os rios onde se pratica pesca esportiva, algumas atividades náuticas e banho.

\subsection{Análise do Plano Diretor (Seção V)}

A análise SWOT é considerada "uma ferramenta utilizada para fazer análises de cenário (ou análises de ambiente), sendo usada como base para a gestão e o planejamento estratégico de uma organização" (DAYCHOUW, 2007 apud SILVA et. al., 2011). Nesse caso foi utilizado essa técnica para relacionar alguns 
Revista Nacional de

Gerenciamento de Cidades

dos possíveis pontos fortes e fracos do turismo em llha Solteira, tendo como base as diretrizes de turismo existentes no Plano Diretor do município.

A partir desta análise interna, é possível traçar possíveis ameaças e oportunidades, a partir de aspectos observados e das diretrizes correspondentes. Entende-se como possíveis pontos fortes e fracos, uma vez que a pesquisa foi feita a partir de observações de material coletado online, inventário turístico e de uma visita a campo.

Para gerar resultados mais precisos seriam necessários aliar outros materiais e outros métodos. No entanto foi possível perceber que algumas ações da gestão local estão de acordo parcialmente com as diretrizes do Plano Diretor.

Cabe ressaltar que essa aplicação será apresentada parcialmente, uma vez que alguns resultados ainda estão sendo analisados, uma vez que a pesquisa está ainda em andamento.

Observando o Quadro 1 - Tem-se o texto apresentando as diretrizes do Plano Diretor, e em seguida as análises; O propósito é apresentar um cenário do município de modo claro e conciso. Esse preceito traduz mais rapidez e agilidade ás fases posteriores de planejamento estratégico para a tomada de decisão.

Quadro 1 - Diretrizes do Plano Diretor (I)

\begin{tabular}{|c|c|c|}
\hline Diretriz I & \multicolumn{2}{|c|}{ Análise de Cenário } \\
\hline \multirow{4}{*}{$\begin{array}{l}\text { Buscar apoio e integração } \\
\text { aos macro-programas do } \\
\text { Ministério do Turismo nos } \\
\text { quesitos de fomento (apoio à } \\
\text { atração de investimentos), } \\
\text { financiamento para o turismo, } \\
\text { infra-estrutura, produção } \\
\text { associada ao } \\
\text { qualidade durismo, } \\
\text { turístico, normatização da } \\
\text { atividade turística } \\
\text { (certificações), qualificação } \\
\text { profissional } \\
\text { comercialização } \\
\text { interno e externo), captação, } \\
\text { promoção e participação em } \\
\text { eventos internacionais; }\end{array}$} & Pontos fortes & Oportunidades \\
\hline & $\begin{array}{l}\text { Programa de Regionalização } \\
\text { do Turismo } \\
\text { Participação no Programa de } \\
\text { Municipalização do Turismo } \\
\text { (anterior a 2008) }\end{array}$ & $\begin{array}{l}\text { Integrar-se a outros } \\
\text { programas do ministério do } \\
\text { Turismo } \\
\text { Utilizar os materiais } \\
\text { disponibilizados pelo } \\
\text { Ministério do Turismo, } \\
\text { como por exemplo as } \\
\text { cartilhas }\end{array}$ \\
\hline & Pontos fracos & Ameaças \\
\hline & $\begin{array}{l}\text { Pouca integração com os } \\
\text { programas do Ministério de } \\
\text { Turismo }\end{array}$ & $\begin{array}{l}\text { Falta de interesse do } \\
\text { Ministério do Turismo em } \\
\text { auxiliar a atividade no } \\
\text { município }\end{array}$ \\
\hline
\end{tabular}

Fonte: Autores, 2014. 
Quadro 2 - Diretrizes do Plano Diretor (II)

\begin{tabular}{|c|c|c|}
\hline Diretriz II & \multicolumn{2}{|c|}{ Análise de Cenário } \\
\hline \multirow{4}{*}{$\begin{array}{l}\text { Manter e ampliar a } \\
\text { participação municipal nos } \\
\text { fluxos turísticos de importância } \\
\text { regional e } \\
\text { promovendo e estimulando a } \\
\text { divulgação de eventos e } \\
\text { projetos em todas as } \\
\text { modalidades } \\
\text { empreendimentos comerciais, } \\
\text { de serviços e produtos } \\
\text { turísticos; }\end{array}$} & Pontos fortes & Oportunidades \\
\hline & $\begin{array}{l}\text { Projeto piloto de um roteiro } \\
\text { turístico junto a outros } \\
\text { municípios da região } \\
>\text { Divulgação em jornais online }\end{array}$ & $\begin{array}{l}\text { Desenvolvimento de um } \\
\text { roteiro turístico e circuito } \\
\text { turísticorando regional, } \\
\text { beneficiando os } \\
\text { municípios inseridas no } \\
\text { Tietê Vivo }\end{array}$ \\
\hline & Pontos fracos & Ameaças \\
\hline & $\begin{array}{l}\text { Falta de interesse dos } \\
\text { empreendedores em iniciativa } \\
\text { de fortalecer o turismo receptivo }\end{array}$ & $\begin{array}{l}\text { A demanda regional } \\
\text { (turistas) não conhece } \\
\text { das atividades de turismo } \\
\text { desenvolvidas no } \\
\text { município. }\end{array}$ \\
\hline
\end{tabular}

Fonte: Autores, 2014.

Quadro 3 - Diretrizes do Plano Diretor (IV)

\begin{tabular}{|c|c|c|}
\hline Diretriz IV & \multicolumn{2}{|c|}{ Análise de Cenário } \\
\hline sistematização & Pontos fortes & Oportunidades \\
\hline $\begin{array}{l}\text { levantamento e atualização } \\
\text { de dados e informações } \\
\text { sobre as categorias, a } \\
\text { cadeias de fluxos e produtos } \\
\text { turísticos no município e } \\
\text { região, em parceria com } \\
\text { órgão e institutos de } \\
\text { pesquisa, para atração de }\end{array}$ & $\begin{array}{l}\text { Existência de instituições } \\
\text { locais que poderiam contribuir } \\
\text { com os levantamentos } \\
>\text { Inserção do município na } \\
\text { Região Turística Tietê- Vivo }\end{array}$ & $\begin{array}{l}\text { Realizar estudos de } \\
\text { demanda } \\
\text { Realizar esses } \\
\text { levantamentos com as } \\
\text { instituições locais, como } \\
\text { por exemplo as de ensino } \\
\text { superior e técnico }\end{array}$ \\
\hline investimentos & Pontos fracos & Ameaças \\
\hline $\begin{array}{l}\text { oportunidades de viabilização } \\
\text { de ações } \\
\text { empreendimentos; }\end{array}$ & $\begin{array}{l}\text { Informações } \\
\text { pontuais e isoladas }\end{array}$ & $\begin{array}{l}>\text { Redução e limitação para } \\
\text { atrair investimentos } \\
\text { Os investimentos podem } \\
\text { ser inadequados a } \\
\text { realidade local e regional }\end{array}$ \\
\hline
\end{tabular}

Fonte: Autores, 2014. 
Quadro 4 - Diretrizes do Plano Diretor (V)

\begin{tabular}{|c|c|c|}
\hline Diretriz V & \multicolumn{2}{|c|}{ Análise de Cenário } \\
\hline \multirow{4}{*}{$\begin{array}{lrr}\text { Resgate } & \text { e } & \text { avaliação da } \\
\text { trajetória } & \text { da } & \text { Diretoria } \\
\text { Municipal } & \text { de } & \text { Turismo: } \\
\text { diretrizes, } & \text { diagnósticos, } \\
\text { programas, projetos; }\end{array}$} & Pontos fortes & Oportunidades \\
\hline & $\begin{array}{l}\text { Presença de pessoal técnico } \\
\text { concursado no departamento } \\
\text { de turismo. }\end{array}$ & $\begin{array}{ll} & \text { Aprimorar as políticas, } \\
& \text { ações de turismo } \\
& \text { Rever a efetividade de } \\
& \text { ações anteriores } \\
& \text { Orientar } \\
& \text { possibilidades novas } \\
& \text { estruturação de } \\
& \text { departamentos direta ou } \\
& \text { indiretamente relacionados } \\
& \text { ao turismo }\end{array}$ \\
\hline & Pontos fracos & Ameaças \\
\hline & $\begin{array}{l}\text { Mudança constante da pasta } \\
\text { turismo nas secretarias } \\
\text { municipais alterando e } \\
\text { prejudicando o planejamento } \\
\text { a longo prazo. }\end{array}$ & $\begin{array}{l}\text { Possível falta de ações } \\
\text { conjuntas entre município, } \\
\text { secretaria de estado do } \\
\text { turismo e DADE. }\end{array}$ \\
\hline
\end{tabular}

Fonte: Autores, 2014.

Ao analisar as Diretrizes de turismo do Plano Diretor I, II, IV e V é possível perceber diferentes aspectos correspondentes aos elementos que constituem a atividade turística, como busca por apoio em programas de turismo nacionais, incentivo a diferentes segmentos de turismo, importância do resgate da política Municipal de turismo entre outros aqui não destacados.

Apesar de verificadas as diretrizes de maneira separada, elas estão interrelacionadas, uma vez que o cumprimento de uma ou mais pode contribuir com a execução de outra. Por exemplo: ações que estejam de acordo com as diretrizes I (um) e IV (quatro) tratam de aspectos relacionados a condução da política de Turismo em nível nacional e local que se trabalhadas em conjunto fortalecem os resultados na consolidação do destino turístico. Essa política se reflete diretamente na segmentação de turismo a exemplo dos eventos, existentes no município e que c partir de políticas pró-ativas definem um perfil de visitantes capaz de movimentar a cadeia produtiva do turismo e de outros serviços existentes em Ilha Solteira.

Não obstante, tem-se a esclarecer que outras diretrizes também foram analisadas e deverão compor outros trabalhos, bem como espera-se que essa metodologia de trabalho ora apresentada, possa iniciar a discussão de modelos de 


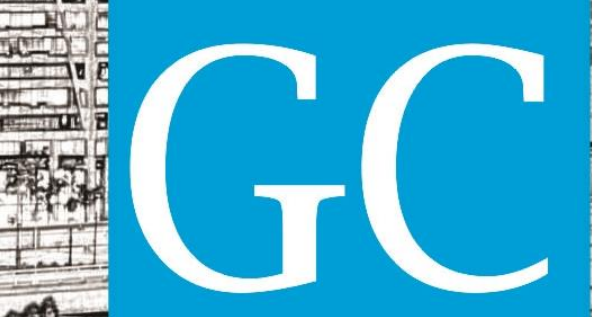

Revista Nacional de

Gerenciamento de Cidades

IGNARRA, Luis Renato. Fundamentos do Turismo. 2 ed. rev. e ampl. São Paulo: Cengage Learning, 2011.

ILHA SOLTEIRA. Lei $\mathrm{N}^{\circ} 270$, de 2 de janeiro de 2013 Dispõe sobre a nova Estrutura da Administração Direta e indireta do Município de llha Solteira e dá outras providências. Câmara Municipal, Ilha Solteira, SP. 2 dez de 2013. Disponível em: $<$ http://www.ilhasolteira.sp.gov.br/index.php?option=com_content\&view=article\&id=3\&ltemid=120>.

Acesso em: 3 ago.2014.

ILHA SOLTEIRA. Lei $N^{\circ} 151$, de 1 de julho de 2008 Institui o Plano Diretor do Município de Ilha Solteira, cria o Conselho da Cidade e dá outras providências. Câmara Municipal, Ilha Solteira, SP. 1 jul.2014. Disponível em: < http://www.llhasolteira.sp.gov.br/planodiretor/>. Acesso em: 20 mar.2014.

PREFEITURA MUNICIPAL DE ILHA SOLTEIRA. Inventário Turístico 2003. Prefeitura Municipal da Estância Turística de llha Solteira, 2003, 106p.

PREFEITURA MUNICIPAL DE ILHA SOLTEIRA. Disponível em: < http://www.ilhasolteira.sp.gov.br/>. Acesso em: 1 mai.2014

SILVA, A. A.; BARBOSA, V. A.; RABELO HENRIQUE, M.; BAPTISTA, J. A. A Utilização da Matriz Swot como Ferramenta Estratégica: um Estudo de Caso em uma Escola de Idioma de São Paulo. VIII Simpósio de Excelência em Gestão e Tecnologia. Disponível em: <http://www.aed.aedb.br/seget/artigos2011.php?pag=113>. Acesso em: 25 mai.2014. 